Gomez de Agüero and coworkers suggest that LCs may help tune the reactivity of the skin's immunologic barrier and that LC dysfunction may contribute to development of allergic contact dermatitis to ubiquitous weak sensitizers (Figure 1).

\section{Acknowledgments}

I thank Stephen I. Katz for helpful discussions. I am supported by the Intramural Research Program (IRP) of the Center for Cancer Research, National Cancer Institute, NIH.

Address correspondence to: Mark C. Udey, Dermatology Branch, CCR, NCI, NIH, Building 10, Room 12N238, Bethesda, Maryland 20892-1908, USA. Phone: 301.496.2481; Fax: 301.496.5370; E-mail: udey@helix.nih.gov.

1. Kubo A, Nagao K, Amagai M. Epidermal barrier dysfunction and cutaneous sensitization in atopic disease. J Clin Invest. 2012;122(2):440-447.

2. Cashman MW, Reutemann PA, Ehrlich A. Contact dermatitis in the United States: Epidemiology, economic impact, and workplace prevention. Dermatol Clin. 2012;30(1):87-98.

3. Kaplan DH, Igyarto BZ, Gaspari AA. Early immune events in the induction of allergic contact dermati- tis. Nature Rev Immunol. 2012;12(2):114-124.

4. Merad M, Ginhoux F, Collin M. Origin, homeostasis and function of Langerhans cells and other langerin-expressing dendritic cells. Nature Rev Immunol. 2008;8(12):935-947

5. Guilliams M, et al. DC lineage and subsets. Eur J Immunol. 2010;40(8):2085-2130.

6. Henri S, et al. Disentangling the complexity of the skin dendritic cell network. Immunol Cell Biol. 2010;88(4):366-375.

7. Bennett CL, et al. Inducible ablation of mouse Langerhans cells diminishes but fails to abrogate contact hypersensitivity. J Cell Biol. 2005;169(4):569-576.

8. Kissenpfennig A, et al. Dynamics and function of Langerhans cells in vivo: Dermal dendritic cells colonize lymph node areas distinct from slower migrating Langerhans cells. Immunity. 2005;22(5):643-654.

9. Kaplan DH, Jenison MC, Saeland S, Shlomchik WD, Shlomchik MJ. Epidermal Langerhans celldeficient mice develop enhanced contact hypersensitivity. Immunity. 2005;23(6):611-620.

10. Kaplan DH, Kissenpfennig A, Clausen BE Insights into Langerhans cell function from Langerhans cell ablation models. Eur J Immunol. 2008; 38(9):2369-2376

11. Igyarto BZ, et al. Langerhans cells suppress contact hypersensitivity responses via cognate CD4 interaction and Langerhans cell-derived IL-10. J Immunol. 2009;183(8):5085-5093.

12. Obhrai JS, et al. Langerhans cells are not required for efficient skin graft rejection. J Invest Dermatol. 2008;128(8):1950-1955

13. Bursch LS, Rich BE, Hogquist KA. Langerhans cells are not required for the CD8 T cell response to epidermal self-antigens. JImmunol. 2009;182(8):4657-4664.
14. Li H, et al. Langerhans cells are not required for graftversus-host disease. Blood. 2011;117(2):697-707.

15. Allan RS, et al. Epidermal viral immunity induced by CD $8 \alpha+$ dendritic cells but not by Langerhans cells. Science. 2003;301(5641):1925-1928.

16. Kautz-Neu K, et al. Langerhans cells are negative regulators of the anti-Leischmania response. J Exp Med. 2011;208(5):885-8891.

17. Igyarto BZ, et al. Skin-resident murine dendritic cell subsets promote distinct and opposing antigen-specific $\mathrm{T}$ helper cell responses. Immunity. 2011:35(2):260-272.

18. Nagao K, et al. Murine epidermal Langerhans cells and langerin-expressing dermal dendritic cells are unrelated and exhibit distinct functions. Proc Natl Acad Sci U S A. 2009;106(9):3312-3317.

19. Ouchi $\mathrm{T}$, et al. Langerhans cell antigen capture through tight junctions confers preemptive immunity in experimental staphylococcal scalded skin syndrome. J Exp Med. 2011;208(13):2607-2613.

20. Gomez de Agüero M, et al. Langerhans cells protect from allergic contact dermatitis in mice by tolerizing $\mathrm{CD}^{+} \mathrm{T}$ cells and activating Foxp $3^{+}$regulatory T cells. J Clin Invest. 2012;122(5):1700-1711.

21. Dearman RJ, Cumberbatch M, Hilton J, Fielding $\mathrm{H}$, Basketter KI. A re-appraisal of skin-sensitizing activity of 2, 4-dinitrothiocyanobenzene. Food Chem Toxicol. 1997;35(2):261-269.

22. Iijima M, Katz SI. Specific immunologic tolerance to dinitroflurobenzene following topical application of dinitrothicyanobezene: Modulation by suppressor T cells. J Invest Dermatol. 1983;81(4):325-330.

23. Watanabe $\mathrm{H}$, et al. Danger signaling through the inflammasome acts as a master switch between tolerance and sensitization. J Immunol. 2008; 180(9):5826-5832.

\title{
Treating myeloma cast nephropathy without treating myeloma
}

\author{
Nelson Leung \\ Division of Nephrology and Hypertension, Mayo Clinic, Rochester, Minnesota, USA.
}

\begin{abstract}
Cast nephropathy is the result of coprecipitation of immunoglobulin free light chains (FLCs) with Tamm-Horsfall glycoprotein (THP). It is a hallmark of multiple myeloma that has significant consequences. Treatment strategies in the past focused on reduction of serum FLC by control of the myeloma. In this issue, Ying et al. report on their successful synthesis of a cyclized competitor peptide that blocks the binding of FLC to THP. In animal studies, this cyclized peptide was capable of reducing cast formation and kidney injury, representing a novel treatment strategy for cast nephropathy that does not depend on the responsiveness of the myeloma to chemotherapy.
\end{abstract}

Sixty-one years passed between the description of Bence Jones proteinuria and the first use of the term "myeloma kidney," by Alfred von Decastello in 1909, to describe the tubu-

Conflict of interest: The author has declared that no conflict of interest exists.

Citation for this article: $J$ Clin Invest.

2012;122(5):1605-1608. doi:10.1172/JCI63248. lar plugging by an amorphous substance in the kidney of myeloma patients (1). Oliver's "cast nephropathy" later replaced it, in 1945, and remains in use today (2). So why was there such a delay in recognizing the nephrotoxic potential of Bence Jones protein $(\mathrm{BJP})$ ? In modern times, renal impairment is accepted as a frequent occurrence in myeloma patients and is one of the diagnostic criteria of symptomatic multiple myeloma (3). The reason that physicians in the late 19th century failed to recognize the nephrotoxicity of BJP can at least be partly attributed to Thomas McBean, the now-famous patient whose urine was studied by William Macintyre, Thomas Watson, and Henry Bence Jones, who had grossly and microscopically normal kidneys despite excreting a calculated $67 \mathrm{~g} / \mathrm{d}$ of protein (4). The same phenomenon has been reported in modern literature, confirming that at least in some patients, a massive amount of Bence Jones proteinuria can have little negative effect on the kidney (5). Part of the mystery was solved in the 1950s by Korngold and Lipari when they discovered BJP actually referred to two different myeloma proteins ( $\kappa$ and $\lambda$, later named in honor of them) (1). Edelman and Gally later identified these proteins as 


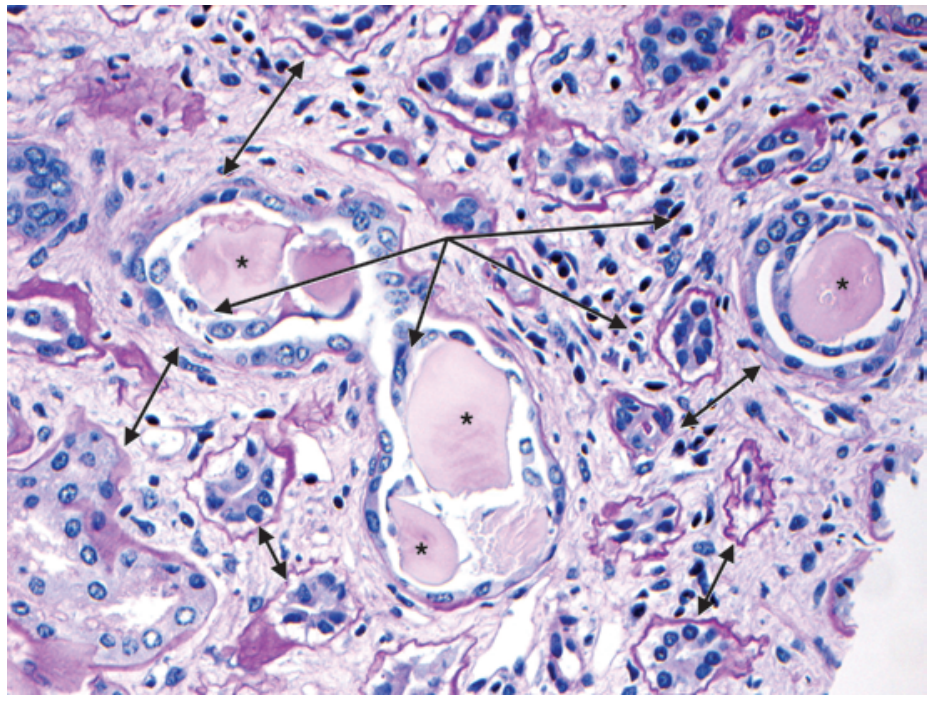

immunoglobulin light chains and showed that BJP from each individual patient was identical to the monoclonal light chain in his/her blood. Each patient would generally produce either a $\kappa$ or a $\lambda$ BJP corresponding to the light chain restriction of his/her myeloma (1). The final piece of the puzzle finally came to light in the 1980s when Tamm-Horsfall glycoprotein (THP, also known as uromodulin), the most abundant protein in human urine, was found in the casts along with monoclonal light chain (6). Cast nephropathy occurs when BJP and THP bind and coprecipitate (6). Since the affinity for THP varies from one light chain to the next, the risk of developing cast nephropathy varies from patient to patient.

We have learned a great deal since, and mostly through the work of Paul Sanders. For over 20 years, Sanders and his lab have detailed the interactions between BJP and THP, discovered factors that promote and inhibit their coprecipitation, described the binding site of THP and $\mathrm{BJP}$, and introduced the basis for treatment strategies $(2,6-8)$. Now, in their latest manuscript, by Ying et al., published in this issue of the JCI, the Sanders group again expands our horizon by describing a completely novel treatment approach for cast nephropathy (9).

\section{Cast nephropathy in multiple myeloma}

Cast nephropathy is the most common form of kidney disease in patients with multiple myeloma, accounting for at least two-thirds of the renal pathologies (10). The coprecipitation of BJP with THP obstructs the ascending limb of the loop of Henle, resulting in rapid decline in renal function (Figure 1). The light chain casts generate intense inflammation via the activation of $\mathrm{c}-\mathrm{Src}$ and NF- $\mathrm{KB}$, and subsequent chemotaxis of immune cells leads to further damage of the kidney (11). If the obstruction is not eliminated, the damage becomes irreversible. Irreversible renal failure has been associated with poor outcome in these patients $(12,13)$. Cast nephropathy, however, is just one of many diseases associated with monoclonal immunoglobulins. Others include monoclonal immunoglobulin deposition disease (MIDD), immunoglobulin light and heavy chain amyloidosis (AL and $\mathrm{AH}$ ), cryoglobulinemic glomerulonephritis, fibrillary glomerulonephritis, immunotactoid glomerulonephritis, acquired Fanconi syndrome, and proliferative glomerulonephritis with monoclonal IgG deposits (10). These diseases differ in location of damage within the nephron, presentation, clinical course, and response to therapy. It is therefore important to confirm the source of renal disease when starting treatment. Unfortunately, distinguishing one etiology from another may be challenging without a kidney biopsy.

The current therapeutic approaches focus on the reduction of the serum free light chain (sFLC). This is mainly done by killing the myeloma plasma cells. Studies suggest a rapid reduction of sFLC by a minimum of $50 \%-60 \%$ is required for renal recovery in patients with proven cast nephropathy $(14,15)$. Prior to the development of the novel chemotherapeutic

\section{Figure 1}

Light microscopy of a kidney with cast nephropathy stained with PAS stain. Multiple distal tubules are filled with PAS-negative casts (asterisks). Some of the cast have a fractured appearance. An inflammatory cellular reaction is seen surrounding the casts (single-headed arrows). Inflammatory infiltrates (single-headed arrows) are seen in the interstitium of the kidney, usually near obstructed tubules. All of these are characteristic features of cast nephropathy. Increased spacing (double-headed arrows) between tubules throughout the biopsy indicates either edema (acute) or tubular atrophy (chronic) and is the result of the injury from the casts. Normally tubules should be lined back to back with each other. agents (bortezomib, thalidomide, and lenalidomide), renal recovery rates were low, ranging between $26 \%$ and $58 \%(12,13)$. To augment the effects of chemotherapy, plasmapheresis (extracorporeal removal) had been employed, but its efficacy could not be consistently demonstrated (15). A higher rate $(86 \%)$ of renal recovery was reported in a smaller retrospective study using bortezomib-based regimens with plasmapheresis, which targeted a minimum sFLC reduction of $50 \%$ (16). A similar strategy of combining novel agents with extracorporeal removal of sFLC has been fashioned using high cutoff (up to $50 \mathrm{kD}$ ) dialyzers, which allow the sFLC to freely pass through the filter (17). The success of this strategy has inspired several randomized trials that are currently ongoing.

\section{New insight for new strategies}

The main problem with current therapeutic strategies is the dependence on sFLC reduction. Currently, no therapy is $100 \%$ effective against multiple myeloma (18). It remains to be determined whether extracorporeal devices can reduce sFLC enough to affect renal recovery if the patient is refractory to chemotherapy. This is why the study by Ying et al. (9) is so important to this field: it completely bypasses the need to control the myeloma. Having previously characterized the FLC-binding site of THP (7), the authors were able to construct a competitive inhibitor peptide (AHXCLSADSSGSYLYVCKK) capable of interrupting the binding between FLC and THP, thus preventing obstruction (Figure 2). The activity was further enhanced by 
A

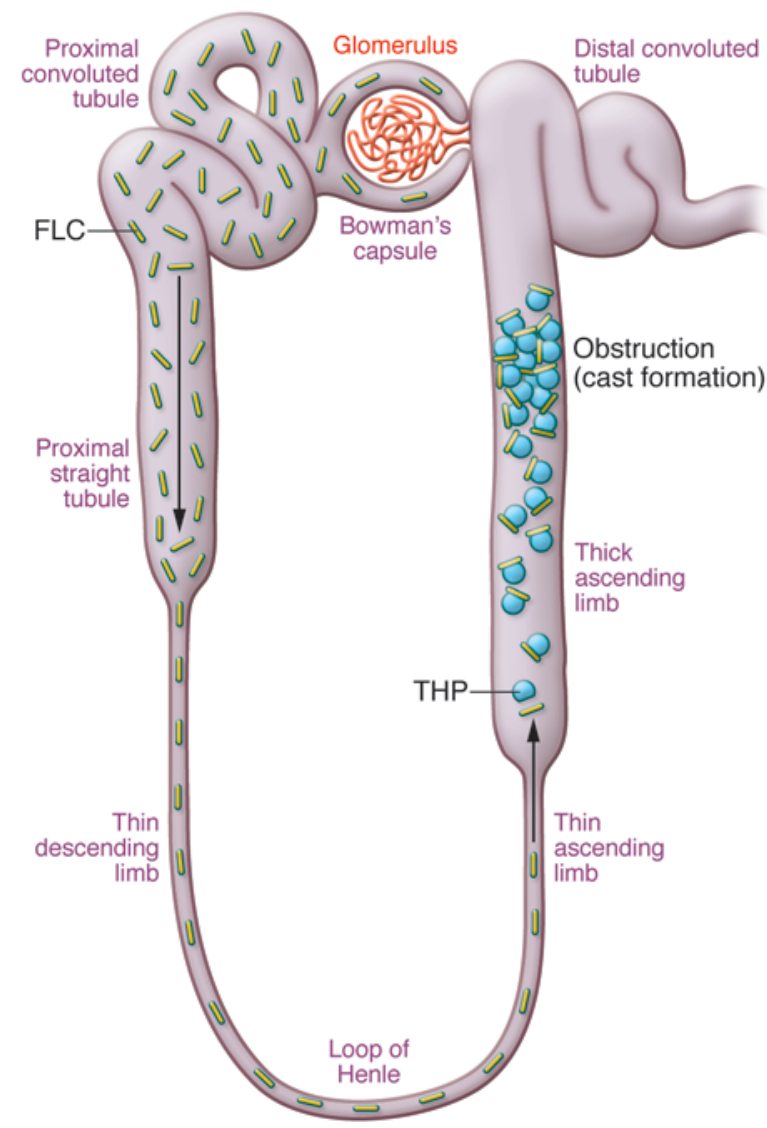

B

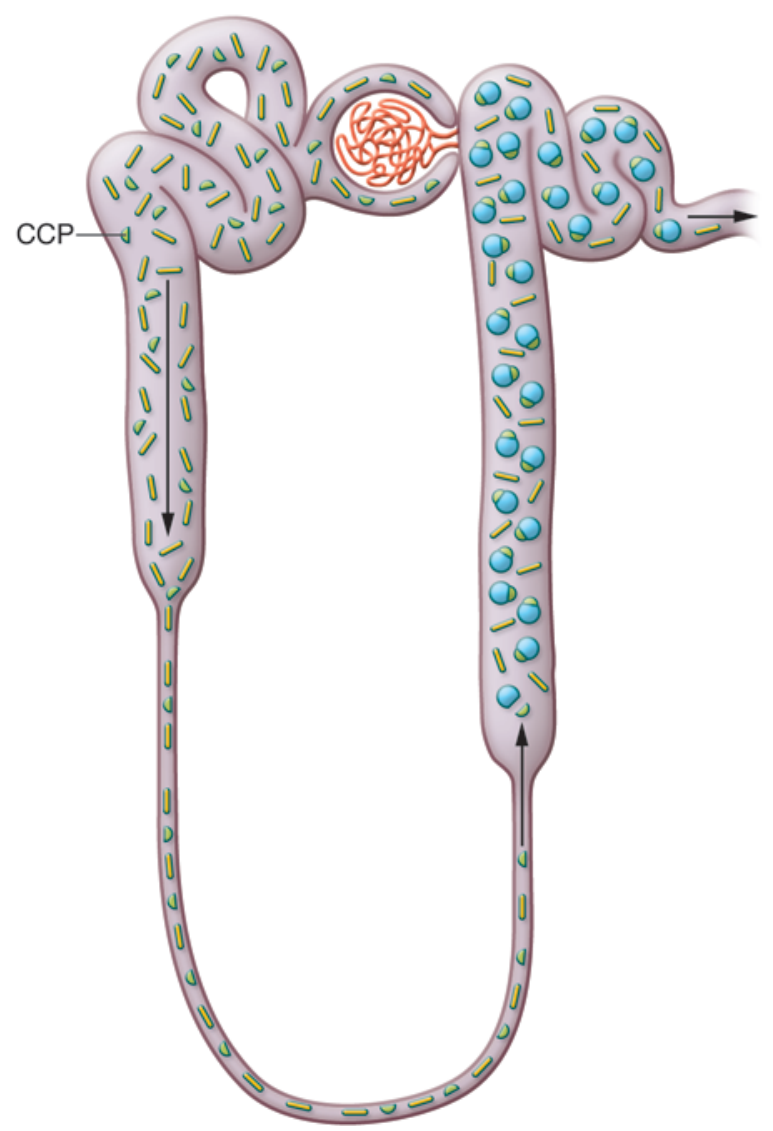

\section{Figure 2}

Treatment of cast nephropathy by targeting THP and FLC interaction. (A) Excessive monoclonal FLC is filtered and binds with THP in the ascending limb of the loop of Henle, resulting in obstruction and cast nephropathy. (B) In the presence of cyclized competitor peptide (CCP), the binding site of THP is blocked, thus preventing FLC from binding and coprecipitation with it. FLC and THP both pass freely through the nephron.

the addition of cysteine residues to the termini of the peptide, which allowed the peptide to be cyclized via an intramolecular disulfide bond. Ying et al. showed in animal studies the cyclized inhibitor peptide was able to prevent cast formation and, more importantly, prevented renal impairment even after cast formation had already occurred (9). The one limitation of this work is that the experiment only allowed four hours between the infusion of the light chain and the inhibitor. Clinical utility will greatly depend on future studies that can demonstrate activity after longer delays, since patients with renal failure from cast nephropathy may present several days to weeks after the initial renal injury.

The cyclized competitor peptide described by Ying et al. is not the first agent to bypass the need for sFLC reduction in the treatment of cast nephropathy. The polypeptide pituitary adenylate cyclase-activating polypeptide with 38 residues (PACAP38) has demonstrated high activity at blocking cellular damage from sFLC in an in vitro setting. However, the in vivo studies so far only looked at its ability to inhibit TNF- $\alpha$ production and did not evaluate its ability to prevent or reverse renal failure (19). Similarly, bortezomib has been shown to reduce the activation of several pathologic pathways, including cSRC and NfKB (11), though it is probably insufficient to reverse renal failure by cast nephropathy as a single agent.

\section{Remaining questions}

The therapeutic potential cyclized peptide AHXCLSADSSGSYLYVCKK offers is very appealing, but many questions remain. First, how competitive is the cyclized peptide against sFLC? Can this cyclized peptide overcome levels of sFLC even greater than $10,000 \mathrm{mg} / \mathrm{dl}$, which have been reported in some patients? How soon does it need to be administered in order for it to be effective? Will it work in severe renal failure where filtration may be hindered? Does it need to enter the urinary space in order for it to block the THPbinding site? What other proteins does it bind? These and other questions will no doubt need to be answered as we explore its therapeutic potential.

However, whether or not this particular protein will have therapeutic uses, the concept will no doubt stimulate new therapeutic strategies for this disease. In this regard, the work of Ying et al. (9) represents the latest chapter in the history of cast nephropathy, which began with the determination that the protein in McBean's urine was a "deutoxide of albumen" and the recommendation by Bence Jones that it "must again be looked for in acute cases of mollities ossium" (4). The possibility of treating cast nephropathy without effectively treating the hematologic disease opens many possibilities. For the first time, patients 
whose myeloma is refractory to treatment might still recover their renal function. Moreover, cyclized peptides such as the one described can also help patients with monoclonal gammopathy-related kidney diseases. Many of these patients have nonmalignant lymphoproliferative or plasma cell disorder that would not require treatment if not for the renal complication (10). Therapeutic strategies that target the monoclonal protein rather than the plasma cell are extremely attractive because they would avoid the use of toxic chemotherapy in those patients who do not have a malignancy condition. This strategy could be quite useful in patients with AL amyloidosis who may be too frail to go through chemotherapy. The potential treatment opportunities of this concept represent new and less toxic treatments for the entire range of plasma cell diseases.

Address correspondence to: Nelson Leung, 200 First Street SW, Rochester, Minnesota 55905, USA. Phone: 507.266.7083; Fax: 507.266.7891; E-mail: Leung.nelson@ mayo.edu.
1. Steensma DP, Kyle RA. A history of the kidney in plasma cell disorders. Contrib Nephrol. 2007;153:5-24.

2. Sanders PW. Pathogenesis and treatment of myeloma kidney. J Lab Clin Med. 1994;124(4):484-488.

3. Dimopoulos MA, et al. Renal impairment in patients with multiple myeloma: a consensus statement on behalf of the International Myeloma Working Group. J Clin Oncol. 2010;28(33):4976-4984.

4. Bence Jones $\mathrm{H}$. On a new substance occurring in the urine of a patient with mollities ossium. Phil Trans R Soc London. 1848;138:55-62.

5. Woodruff R, Sweet B. Multiple myeloma with massive Bence Jones proteinuria and preservation of renal function. Aust NZ J Med. 1977;7(1):60-62.

6. Sanders PW, Booker BB, Bishop JB, Cheung HC. Mechanisms of intranephronal proteinaceous cast formation by low molecular weight proteins. J Clin Invest. 1990;85(2):570-576.

7. Ying WZ, Sanders PW. Mapping the binding domain of immunoglobulin light chains for Tamm-Horsfall protein. Am J Pathol. 2001;158(5):1859-1866.

8. Sanders PW, Booker BB. Pathobiology of cast nephropathy from human Bence Jones proteins. J Clin Invest. 1992;89(2):630-639.

9. Ying WZ, Allen CE, Curtis LM, Aaron KJ, Sanders PW. Mechanism and prevention of acute kidney injury from cast nephropathy in a rodent model. J Clin Invest. 2012;122(5):1777-1785.

10. Leung N, Rajkumar SV. Renal manifestations of plasma cell disorders. Am J Kidney Dis. 2007; 50(1):155-165

11. Ying WZ, Wang PX, Aaron KJ, Basnayake K, Sanders PW. Immunoglobulin light chains activate nuclear factor-kappaB in renal epithelial cells through a Src-dependent mechanism. Blood. 2011;
117(4):1301-1307.

12. Knudsen LM, Hjorth M, Hippe E. Renal failure in multiple myeloma: reversibility and impact on the prognosis. Nordic Myeloma Study Group. Eur J Haematol. 2000;65(3):175-181.

13. Blade J, et al. Renal failure in multiple myeloma: presenting features and predictors of outcome in 94 patients from a single institution. Arch Intern Med. 1998;158(17):1889-1893.

14. Hutchison CA, et al. Early reduction of serumfree light chains associates with renal recovery in myeloma kidney. J Am Soc Nephrol. 2011; 22(6):1129-1136

15. Leung $\mathrm{N}$, et al. Improvement of cast nephropathy with plasma exchange depends on the diagnosis and on reduction of serum free light chains. Kidney Int. 2008;73(11):1282-1288.

16. Burnette BL, Leung N, Rajkumar SV. Renal improvement in myeloma with bortezomib plus plasma exchange. N Engl J Med. 2011;364(24):2365-2366.

17. Hutchison CA, et al. Efficient removal of immunoglobulin free light chains by hemodialysis for multiple myeloma: in vitro and in vivo studies. J Am Soc Nephrol. 2007;18(3):886-895.

18. Barlogie B, et al. Long-term follow-up of autotransplantation trials for multiple myeloma: update of protocols conducted by the intergroupe francophone du myelome, southwest oncology group, and university of arkansas for medical sciences. J Clin Oncol. 2010;28(7):1209-1214.

19. Arimura A, Li M, Batuman V. Potential protective action of pituitary adenylate cyclase-activating polypeptide (PACAP38) on in vitro and in vivo models of myeloma kidney injury. Blood. 2006;107(2):661-668

\title{
NADPH oxidase regulates efficacy of vaccination in aspergillosis
}

\author{
George S. Deepe Jr.
}

Division of Infectious Diseases, University of Cincinnati College of Medicine, and the Veterans Affairs Hospital, Cincinnati, Ohio, USA.

\begin{abstract}
Invasive aspergillosis is often a consequence of immune suppression, and accumulating evidence points to a role for adaptive immunity. Hence, it may be possible to manipulate the adaptive immune system to enhance protective immunity in at-risk individuals. In this issue of the JCI, De Luca and colleagues describe the ontogeny of adaptive immune responses to murine aspergillosis infection in relation to vaccination. Their thought-provoking findings reveal the complexities of vaccine-induced immunity and could be used to improve vaccine efficacy.
\end{abstract}

Aspergillus spp constitute an omnipresent mold, found in air, water, and soil. Conidia - spores that are released from hyphae - are inhaled daily by humans. The major variable in human exposure is the number of particles, and this value may be low indoors and strikingly high in areas that

Conflict of interest: The author has declared that no conflict of interest exists.

Citation for this article: J Clin Invest. 2012; 122(5):1608-1611. doi:10.1172/JCI63417. contain decaying matter. The species of Aspergillus that cause invasive infection are limited, but these share an important trait: the ability to grow at $37^{\circ} \mathrm{C}$, human body temperature. Among those that cause invasive disease in humans, A. fumigatus is the most prevalent followed, by $A$. flavus $(1,2)$.

Despite constant contact with conidia, the immunocompetent host rarely develops invasive disease, largely because immune defenses in lungs are highly effective. Infec- tion is initiated when host resistance is dampened, and spores convert into hyphae that disseminate through the vascular system. Several risk factors predispose individuals to infection with Aspergillus. Chief among them are the use of glucocorticoids to treat inflammatory disorders, severe neutropenia induced by cytotoxic agents, or, less frequently, the use of TNF- $\alpha$ antagonists. The risk of disease acquisition escalates in parallel with the length of glucocorticoid administration or the duration of neutropenia (1). Qualitative defects in neutrophil function also increase the probability of acquiring disease. One of the more common disorders associated with dysfunctional phagocytes is chronic granulomatous disease (CGD), an inherited disease in which the fundamental genetic defect is in the assembly of the NADPH oxidase (3). Since the leukocytes from these patients fail to mount a vigor- 